Cahiers $d u$ MONDE RUSSE

\section{Cahiers du monde russe}

Russie - Empire russe - Union soviétique et États indépendants

$55 / 3-4 \mid 2014$

Varia

\title{
Rachel Mazuy (édité et présenté par), Moscou - Caucase été 34, Lettres de Marguerite et Jean-Richard Bloch
}

\section{Sophie Cœuré}

\section{(2) OpenEdition}

1 Journals

\section{Édition électronique}

URL : http://journals.openedition.org/monderusse/8069

DOI : 10.4000/monderusse.8069

ISSN : $1777-5388$

Éditeur

Éditions de l'EHESS

\section{Édition imprimée}

Date de publication : 1 juillet 2014

Pagination : 410-412

ISBN : 978-2-7132-2441-6

ISSN : $1252-6576$

\section{Référence électronique}

Sophie Cœuré, «Rachel Mazuy (édité et présenté par), Moscou - Caucase été 34, Lettres de Marguerite et Jean-Richard Bloch », Cahiers du monde russe [En ligne], 55/3-4 | 2014, mis en ligne le 13 avril 2015, Consulté le 23 septembre 2020. URL : http://journals.openedition.org/monderusse/8069 ; DOI : https://doi.org/10.4000/monderusse.8069

Ce document a été généré automatiquement le 23 septembre 2020.

(c) École des hautes études en sciences sociales 


\title{
Rachel Mazuy (édité et présenté par), Moscou - Caucase été 34, Lettres de Marguerite et Jean-Richard Bloch
}

\author{
Sophie Cœuré
}

\section{RÉFÉRENCE}

Rachel MAZUY, édité et présenté par, Moscou - Caucase été 34, Lettres de Marguerite et Jean-Richard Bloch, Paris : Cahiers Jean-Richard Bloch, $\mathrm{n}^{\circ}$ 19, 2013, $259 \mathrm{p}$.

1 Si les travaux sur le voyage en URSS et la politique culturelle soviétique, tant intérieure qu'extérieure, se sont multipliés ces dernières années grâce à l'ouverture de nouvelles archives, les éditions critiques donnant accès directement aux documents et témoignages contemporains demeurent relativement rares. Il faut donc saluer le travail de Rachel Mazuy qui offre, avec cette édition minutieuse, les lettres de Marguerite et Jean-Richard Bloch à leurs proches. Jean-Richard Bloch fut l'un des quatre invités français parmi les 591 délégués, dont 40 étrangers, du premier congrès des écrivains soviétiques qui s'est déroulé du 17 août au 2 septembre 1934, avec Louis Aragon, André Malraux, Paul Nizan et Vladimir Pozner. Le séjour du couple se prolongea à Moscou (à l'occasion du festival théâtral de septembre 1934), en Arménie, Géorgie et Azerbaïdjan. Début octobre, Marguerite regagna la France, tandis que Jean-Richard resta à Moscou jusqu'au 20 décembre 1934.

2 Ce long voyage en Union soviétique se place à un moment clé pour le statut de l'écrivain et le débat sur le réalisme socialiste. C'est un moment clé également pour le couple Bloch, qui rencontre pour la première fois une réalité soviétique ardemment attendue. Jean-Richard Bloch, membre du mouvement "Clarté ", avait voté comme militant socialiste le rattachement du parti à la $\mathrm{III}^{\mathrm{e}}$ Internationale en 1920 , mais s'était 
éloigné du parti communiste « bolchevisé » pour se consacrer à son œuvre d'écrivain et d'essayiste. Il fait partie, dès la fin des années 1920, des intellectuels ciblés par la politique d'influence soviétique, au croisement de l'action paradiplomatique de la Société pour les relations culturelles avec l'étranger (VOKS), des milieux kominterniens de l'entourage de Willi Münzenberg, et du philosoviétisme français avec Anatole de Monzie ou Lucien Vogel. Rachel Mazuy retrace dans son introduction le processus d'invitation au congrès, sans tout à fait éclaircir les raisons du choix par Moscou d'un écrivain qui n'est pas encore un compagnon de route de premier plan. Cette sollicitation rencontre opportunément les attentes de J.-R. Bloch, profondément alarmé par les dangers croissants du fascisme et du national-socialisme en France et en Europe, et de plus en plus convaincu par la politique soviétique. Marguerite Herzog, qui est la sœur d'André Maurois et l'épouse de Jean-Richard Bloch depuis 1907, partage ses idéaux de gauche et sa proximité avec les milieux littéraires parisiens. Elle est dite " sans profession ", ce qui veut dire qu'elle élève ses quatre enfants et fait le secrétariat de son époux.

3 C'est donc très logiquement que Marguerite Bloch, emportant papier à lettre et machine à écrire, se charge des «lettres-récit ", dont elle est le plus souvent l'auteure, parfois les dactylographie sous la dictée de son mari. Souvent tapées à plusieurs exemplaires, destinées à circuler parmi les proches, les lettres sont rassemblées sous forme de scrapbook avant l'heure et illustrées de timbres, invitations, billets, cartes postales, photographies. Caché dans le jardin de la maison familiale du Poitou, le volume survit à son occupation par des officiers allemands et sera retrouvé par les Bloch à leur retour d'URSS, où ils se réfugient entre 1941 et 1945. Cette archive rare et fragile, partiellement rongée par l'humidité, est complétée au jour le jour par un carnet de notes, demeuré inédit ${ }^{1}$.

4 Les lettres, principalement destinées aux enfants Bloch dont certains sont déjà engagés en politique, entrecroisent la narration des choses vues, l'analyse, et le rendu parfois littéral des explications fournies par les accompagnateurs. Leur lecture est nécessairement orientée ex post par la production historique critique documentant les voyages en Union soviétique, ainsi que par la connaissance du destin ultérieur des Bloch : leur choix d'adhérer au PCF à la toute fin des années 1930, leur refuge à Moscou et Kazan', leur fidélité au stalinisme dans le double contexte de la France de l'après-guerre et des terribles épreuves familiales liées à la politique antisémite et à la répression de la résistance. On pourra donc chercher à bon droit dans ces notes l'illustration d'un processus de conviction, y trouver les signaux d'un voyage classiquement surchargé, encadré, rétribué matériellement et symboliquement, y repérer les indices de doute devant l'accueil «de nanabs ", les banquets somptueux, le wagon spécial trouvé " par miracle » pour acheminer le couple et ses accompagnateurs vers le Caucase.

5 L'expérience soviétique sera restituée par Jean-Richard Bloch dans de multiples articles et conférences, mais non dans un ouvrage "retour d'URSS", manière de faire comparable à celle de Paul Nizan. Marguerite Bloch ne publiera rien, pas même ses mémoires, contrairement à Henriette Nizan et Clara Malraux. Elle évite les «digressions générales » et manie une plume vivante et concrète, son mari se faisant quant à lui plus politique et synthétique. Cette lecture "genrée » demande à être affinée $^{2}$. Elle fait comprendre quoi qu'il en soit un regard direct sur l'URSS, regard dégagé des intérêts matériels (commande de scénarios, traductions...), professionnels et 
politiques personnels, qui sont ceux de son mari. Jean-Richard Bloch est ainsi engagé dans un débat avec Radek sur "l'individualisme » littéraire, et s'empêtre dans une attitude ambiguë dans la mobilisation pour Victor Serge, arrêté et envoyé en relégation l'année précédente.

La fin de l'année 1934 se prête à un panorama apaisé et positif de l'URSS en construction qui, comme l'a montré Michaël David-Fox ${ }^{3}$, s'offre en spectacle à elle-même tout autant qu'aux visiteurs étrangers. La visite se déroule de Moscou au Caucase, de parades en usines, de kolkhozes en maternités, de dîners nocturnes en contemplation des paysages, dans une "atmosphère excessivement bon enfant ». La dimension esthétique et épique du voyage apparaît dans des épisodes qui touchent au "prodige ", tel celui du Samoyède anthropophage devenu docteur en philosophie... Marguerite Bloch révèle un talent du portrait croqué sur le vif : les Malraux « couple d'une intellectualité formidable ", " des gens terribles », Eisenstein "homme dont la conversation égale les films ", Meyerhold "vieux farceur, fin et malicieux », etc. Elle offre un récit saisissant et cinématographique du banquet tenu chez Gor'kij. Ses lettres sont également très riches en notations fines sur la médiation avec les élites soviétiques, qui passe par la traduction du russe (ainsi un toast porté par Kaganovi@, traduit par un Allemand, "mettait le cerveau en bouillie»), parfois par la double traduction de l'arménien vers le russe puis le français.

Cette plongée dans l'utopie soviétique réalisée est aussi pour Marguerite et Jean-Richard Bloch, un grand voyage exotique, presque de grandes vacances, et l'occasion de rencontres enthousiasmantes. Les soigneuses notes biographiques de Rachel Mazuy restituent leur dimension tragique au destin des hommes et des femmes, rencontrés en URSS alors qu'ils partagent avec les invités étrangers toute l'énergie de leur engagement, et qui seront dans leur quasi-totalité victimes de la répression stalinienne. Il reste que ces lettres invitent à compléter la lecture critique et savante de l'expérience occidentale de l'URSS par une approche plus empathique de ce qui fut, comme l'écrit Marguerite Bloch à propos de l'Arménie, un « voyage extraordinaire ».

\section{NOTES}

1. L'un et l'autre se trouvent au fonds Bloch de la BnF. Cf. Ludmila Stern, « Carnet de voyage en URSS (1934) de Marguerite Bloch ", Cahiers Jean-Richard Bloch, " Hommage à Nicole Racine », 20, 2015, à paraître.

2. Cf. Rachel Mazuy, « Marguerite Bloch, une femme d'écrivain en URSS », ibidem.

3. Michaël David-Fox, Showcasing the Great Experiment: Cultural Diplomacy and Western Visitors to the Soviet Union, 1921-1941, Oxford University Press, 2012. 


\section{AUTEURS}

SOPHIE CEEURÉ

Université Paris Diderot- Paris 7 